\title{
Endoscopic closure of an iatrogenic duodenal perforation: a novel technique using endoclips, endoloop, and fibrin glue
}

An 80-year-old woman with a flat duodenal tubulovillous adenoma presented for endoscopic mucosal resection (EMR). This lesion had received treatment with EMR and Nd:YAG laser in the past. The lesion was located in the proximal second portion of duodenum (D2), measured approximately $2 \mathrm{~cm}$, and was half-circumferential from the 12-o'clock to the 6-o'clock position.

The lesion was lifted with submucosal injection of methylene blue and saline. A multibanding cap was used to place ligation bands around two areas for EMR. One area was targeted with a hexagonal snare, and after resection a 1 -cm perforation became obvious at the lateral aspect of D2 ( Fig. 1). Endoscopic clipping of the defect was attempted but, due to the large size of the defect and the wall being taut, the edges were not able to be approximated.

A "clutching rose stems" technique was used to close the defect ( Fig.2), as follows. A total of eight endoclips (Resolution clip; Boston Scientific, Natick, Massachusetts, USA) were placed circumferentially around the perimeter of the wound edge. This was followed by placing a detachable endoloop (Polyloop; Olympus America Inc., Melville, New York, USA) around the perimeter base of the clips. The snare was tightened, which successfully brought all the edges of the wound together, and was then detached. In order to ensure a complete seal, a total of $8 \mathrm{ml}$ of fibrin glue (Tisseel; Baxter, Deerfield, Illinois, USA) was injected at the center of the "rose stems". A large, transparent glue "clot" formed over the entire wound. The total time for endoscopic closure was 45 minutes.

Post procedure, the patient was noted to be asymptomatic despite the presence of free air on abdominal computed tomography (CT). An upper gastrointestinal contrast study failed to show any extravasation of contrast out of the bowel. The patient received nasogastric tube decompression with bowel rest and broad spectrum antibiotic coverage, and had an uneventful hospital course.

Multiple case reports have been published on iatrogenic duodenal perforations closed using endoclips [1-5]. To our knowledge, this is the first case of a duodenal perforation closed using a "clutching rose stems" technique using endoclips, an endoloop, and fibrin glue. In this case, the fibrin glue was essential in sealing the center hole after the endoclips and endoloop had brought the edges of the defect together. In the advent of newer resection techniques, further progress needs to be made in the area of endoscopic closure, such that perforations can easily be managed by the endoscopist.
Endoscopy_UCTN_Code_TTT_1AR_2AI

\section{Competing interests: None}

\section{J. B. Samarasena ${ }^{1}$, Y. Nakai ${ }^{1}$, D. H. Park ${ }^{2}$, T. Iwashita ${ }^{3}$, K. Chang ${ }^{4}$}

${ }^{1}$ Department of Gastroenterology, University of California - Irvine, Orange, California, USA

2 Department of Internal Medicine, Asan Medical Center, University of Ulsan College of Medicine, Seoul, Republic of Korea

${ }^{3}$ First Department of Internal Medicine, Gifu University Hospital, Gifu, Japan

${ }^{4}$ Comprehensive Digestive Disease Center, University of California - Irvine, Orange, California, USA

\section{References}

1 Sanders MK, Malick J, Fasanella KE et al. Endoscopic closure of iatrogenic duodenal perforation during EUS in a patient with unusual anatomy. Gastrointest Endosc 2008; 68: $802-804$

2 Nakagawa $Y$, Nagai T, Soma $W$ et al. Endoscopic closure of a large ERCP-related lateral duodenal perforation by using endoloops and endoclips. Gastrointest Endosc 2010; 72: $216-217$

3 Mutignani M, Iacopini F, Dokas S et al. Successful endoscopic closure of a lateral duodenal perforation at ERCP with fibrin glue. Gastrointest Endosc 2006; 63: 725-727

4 Lee TH, Bang BW, Jeong JI et al. Primary endoscopic approximation suture under cap-

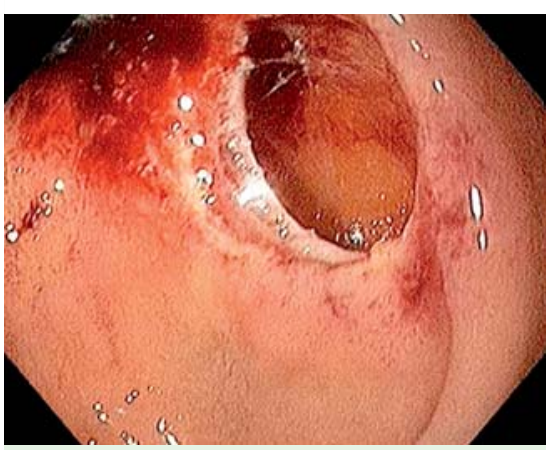

Fig. 1 latrogenic duodenal perforation at the lateral aspect of the proximal second portion of duodenum, after endoscopic mucosal resection (EMR) of a lesion.

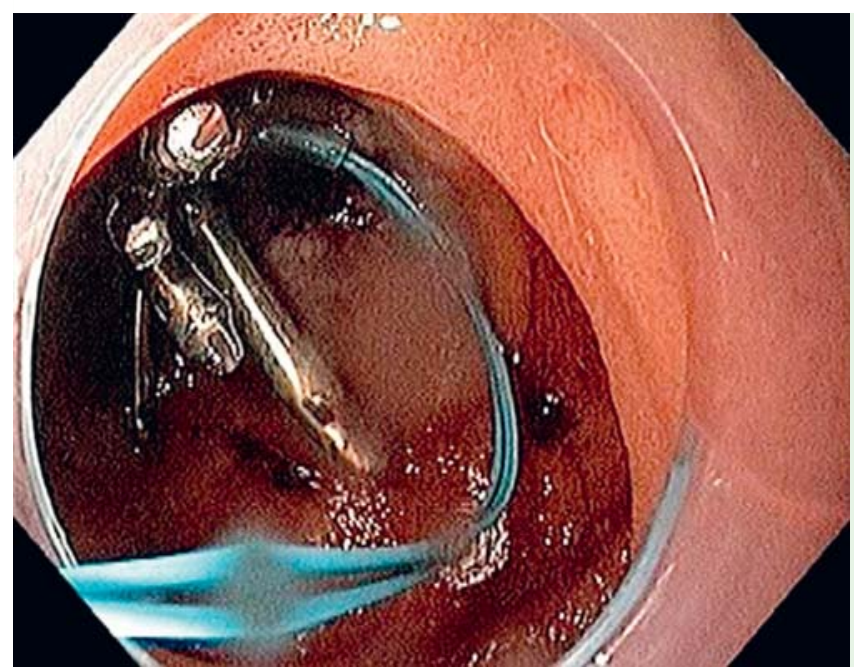

Fig. 2 The duodenal perforation was closed using endoclips and an endoloop, in a "clutching rose stems" technique. 
assisted endoscopy of an ERCP-induced duodenal perforation. World J Gastroenterol 2010; 16: 2305-2310

5 Sebastian S, Byrne AT, Torreggiani WC et al. Endoscopic closure of iatrogenic duodenal perforation during endoscopic ultrasound. Endoscopy 2004; 36: 245
Bibliography

Dol http://dx.doi.org/

10.1055/s-0032-1325738

Endoscopy 2012; 44: E424-E425

(c) Georg Thieme Verlag KG

Stuttgart · New York

ISSN 0013-726X
Corresponding author

J. B. Samarasena, MD

Department of Gastroenterology University of California - Irvine

Suite 400, 333 City Blvd West

Orange

CA 92868

USA

Fax: +1-714-456-7753

jason.samarasena@gmail.com 